\title{
Q\&A: Peter Atkins on writing textbooks
}

\begin{abstract}
The success of Peter Atkins's classic textbook Physical Chemistry led him to trade research for full-time writing and teaching in the 1980s. In the first of a series of five interviews with authors who each write science books for a different audience, Atkins explains how the rewards for textbooks can be great, but the effort needed can affect your research.
\end{abstract}

\section{What is the purpose of a textbook?}

To inspire a mode of thought. Ideally, a book then becomes a companion for life.

\section{What is a good science textbook?}

One that is considerate to the students - one that tries to put itself in their position and to explain and interpret what is going on. The author has to imagine himself as a student, and think and then write down what the student might be puzzling over. It also needs a logical flow.

\section{Did your own teaching experiences influence you?}

Wholly. Being face-to-face with students grappling with concepts is a real education. They say "Yes, I understand"; but there's a dullness about their eyes. So you have another go, and a light goes on. That's the bit you remember when you come to write.

\section{How do textbooks come into being? Who} decides on the subject and scope?

You are constrained by the market. The publisher is alert to what the market needs. In my case, the publisher had received a not-very-good proposal for a physical chemistry book, and came to me and said, can you do better? Sales reps are frequently on the lookout for potential authors; instructors often approach a publisher with a proposal.

\section{What makes you write?}

It is an urge to communicate and share my vision of the world. I've never taken a course on writing. I have a lucid style, and I think I can trace that to two things: one, I read a lot of books at university; two, it is important to have a deeper understanding than the level one wishes to exposit, so that you have the intellectual muscle and confidence.

\section{What are the main challenges?}

Getting the level right. Seeking that balance between completeness and succinctness so the text can be used over a broad spectrum of classes and isn't too long. Major chemistry books have about 1,000 pages, and they grow. Not because of factual content, but because more worked examples are put in.

\section{Your book is in its ninth edition — why so many revisions?}

Revisions have a rhythm that's decided by the market. Higher level texts are on a 4-year cycle; lower level texts on a 3-year cycle. To revise a book takes a year of rewriting and a year of production. When I say rewrite, I mean rewrite - not just tart up. To maintain one's premier position, one has to take revision seriously.

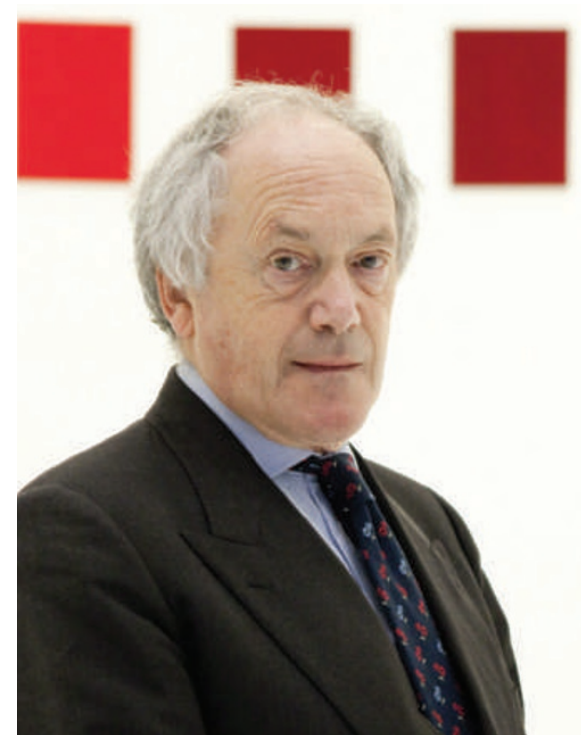

Peter Atkins sees textbooks as a way to capture a mode of thinking.

\section{Does the second-hand market reduce} sales?

Yes - it undermines income streams. In the second year, purchases fall, and in the third year there are none at all. If the second-hand market could be eliminated, books would last longer than 3 years and could be cheaper. There is a way - to produce electronic books [e-books] and kill them after a year.

\section{How has the online shift affected textbooks?}

There are many advantages in the e-book universe. The interactivity is compelling. You have cheaper distribution. Publishers can set the licence to expire to thwart the secondhand market. But there are disadvantages. You lose the serendipity of a real book because browsing is difficult. In an e-book, you're out in a forest and don't know where the edge is, or even if there is an edge.

\section{Is adding online content difficult?}

To produce an e-book you have to be more of an impresario than an author. You have the pictures, the unfolding of different depths of information. It's an extraordinarily demanding task.

\section{Does this make it harder to find good writers?}

It is increasingly difficult for publishers to get people to write textbooks. Heads of department are adamant that their faculty members focus on research, so publishers are finding it difficult to commission people of the quality they need. That becomes a bigger problem when you've got the e-book dimension added in.

What are the rewards for so much effort? There are financial rewards. Beyond that, there are real pleasures in knowing you are helping to mould peoples' attitudes. It's heart-warming that wherever you go in the world, there's a group of people who already know you.

\section{Is it true that authors can make millions} from textbooks?

The financial rewards can be considerable, especially if they lead to other textbook commissions. The largest potential market is the freshman population in North America, around 200,000 students, and authors of textbooks for basic courses can make serious amounts of money. More specialist and graduate markets are much smaller, in the thousands, so earnings are proportionately less.

\section{For those intent on writing a textbook, what is your advice?}

Of course, I'd like to be competition-free. But when I'm gone, the prospective textbook writer should realize that there are immense rewards, not only intellectual. Interview by Nicola Jones, a commissioning editor for Nature's Opinion section. published in 1978 by Oxford University Press. 